\title{
A TWO-GENERATION REPRODUCTIVE TOXICITY STUDY OF BENZOPHENONE IN RATS
}

\author{
Nobuhito HOSHINO ${ }^{1}$, Einosuke TANI ${ }^{1}$, Yumi WAKO ${ }^{2}$ and Kaname TAKAHASHI ${ }^{1}$ \\ Toxicology Division I ${ }^{1}$, and Pathology Division ${ }^{2}$, Kashima Laboratory, Mitsubishi Chemical Safety Institute Ltd, \\ 14 Sunayama, Kamisu-shi, Ibaraki 314-0255, Japan
}

(Accepted October 18, 2005)

\begin{abstract}
The reproductive toxicity of benzophenone (BZP) was evaluated in a two generation test in which male and female Sprague-Dawley (SD) rats, parental (F0) and first generation (F1), were exposed to BZP by feeding diet containing BZP at concentrations of 0 (control), 100, 450 or $2000 \mathrm{ppm}$. With regard to the effects of BZP on the F0 and F1 parental animals, inhibition of body weight gain and food consumption, significantly elevated renal weights, dilatation of the renal proximal tubules, and regeneration of the proximal tubular epithelium were recognized at doses of $450 \mathrm{ppm}$ and $2000 \mathrm{ppm}$, along with an increase in hepatic weight and centrilobular hepatocytic hypertrophy, considered as vital adaptive changes, at the doses of $100 \mathrm{ppm}$ or more. Obvious effects on the endocrine system and reproductive toxicological effects were not found even at the dose of $2000 \mathrm{ppm}$ in the F0 or F1 parent. There were no test substance related changes in the estrous cycle, reproductive capability, delivery and lactation, sperm parameters, serum hormone levels, or necropsy findings. As for effects on the offspring, inhibition of body weight gain was observed in both the F1 and F2 males and females of the $2000 \mathrm{ppm}$ group. No effects of BZP treatment were recognized in the number of male and female F1 or F2 pups delivered, viability, anogenital distance (AGD), physical development, the results of reflex and response tests, or on the observation results of external abnormalities. From the present study of BZP administered to rats over two successive generations, the no observed effect level (NOEL) on the parental animals is concluded to be less than $100 \mathrm{ppm}$. Concerning the effects on the endocrine system and the reproductive toxicity in the parental animals, the NOEL is $2000 \mathrm{ppm}$. In terms of the effects on the offspring, the NOEL is considered to be $450 \mathrm{ppm}$.
\end{abstract}

KEY WORDS: Benzophenone, Two-generation, Reproductive toxicity, Rats

\section{INTRODUCTION}

Benzophenone (BZP) is a common ingredient of medicines and synthetic raw materials used in production of pesticides, aromatics, and ultraviolet-ray absorbents. BZP does not bind to human estrogen receptors (METI, 2002), does not activate transcription through human estrogen receptors (Nishihara et al., 2000), and does not elicit activity in MCF-7 cells, a human breast cancer cell strain (Nakagawa et al., 2000). However, the compound was indicated to have weak estrogenic and anti-estrogenic effects (METI, 2002) in an in vivo uterotrophic assay using ovariectomized rats. There have hitherto been no studies conducted on toxicity of
BZP regarding reproduction and development.

As part of the "Developmental Project of Evaluation and Testing Method for Endocrine Disrupting Effect of Chemical Substances", a research project of the New Energy and Industrial Technology Developmental Organization (NEDO), BZP-mixed feed was administered to rats over two successive generations and effects on the reproductive capability in the parental animals and growth and development of the offspring were investigated.

This study was carried out in accordance with the OECD guideline for the testing of chemicals No.416 (OECD, 1983).

Correspondence: Nobuhito HOSHINO (E-mail: n-hoshino@ankaken.co.jp) 
N. HOSHINO et al.

\section{MATERIALS AND METHODS}

\section{Chemical}

Benzophenone (BZP, CAS No. 119-61-9) was provided by Kanto Chemical Co., (Tokyo, Japan) and mixed into NIH-07M diet (CLEA Japan, Inc.). The BZP used had a purity of $99.98 \%$ or higher (Lot No.: 112D2013).

\section{Animals and housing condition}

International Genetic Standard rats (Crj:CD(SD)IGS, Charles River Japan, Inc. [Astugi breeding center]) were employed. After quarantine and acclimatization for 5 days, healthy rats were subjected to this study, with twenty-four male and female rats constituting each group. Animals were reared on basal diet (NIH-07M, CLEA Japan, Inc.) and tap water irradiated by ultraviolet-ray after filtration through a $5 \mu \mathrm{m}$ filter was given ad libitum using water bottles. They were housed in a breeding room controlled with the temperature at $19.0^{\circ}-25.0^{\circ} \mathrm{C}$, the relative humidity at $35.0 \%-75.0 \%$, the number of ventilation at about 12 times/hour, and the light and dark cycle at $12 \mathrm{hr}$ (turn on at 7 o'clock and off at 19 o'clock). They were placed in polycarbonate cages with bedding for laboratory animals. Administration to the F0 parental animals was started at five weeks old.

\section{Dosing}

In a dose-range finding study, conducted with administration of BZP at doses of 0,600, 2000, 6000 or $20000 \mathrm{ppm}$ for 28 days, emaciation, reduction in body weight and inhibition of food consumption were observed in the males and females of the $20000 \mathrm{ppm}$ group, and all these animals underwent moribund sacrifice. The changes observed in the $6000 \mathrm{ppm}$ group or less included lower values for body weights in the males and females of the $6000 \mathrm{ppm}$ group, and lower values for food consumption in the females of the 2000 and $6000 \mathrm{ppm}$ groups. Elevated absolute and relative hepatic weights were recognized in the males and females of the $600 \mathrm{ppm}$ or higher, along with higher values of absolute and relative renal weights in the males of the $600 \mathrm{ppm}$ or higher group, and liver enlargement in the males of the $600 \mathrm{ppm}$ or more and the females of the $2000 \mathrm{ppm}$ or more. Moreover, with regard to effects on the reproductive organs, the 2000 and 6000 ppm groups showed elevated values for absolute and relative testicular weights, the $6000 \mathrm{ppm}$ group demonstrated low values for absolute and rela- tive prostatic weights, and higher values for relative epididymal weights. A small uterus was found in one animal of the $6000 \mathrm{ppm}$ group. Based on these results, the highest dose for the definitive study was set at 2000 $\mathrm{ppm}$. The intermediate and lowest doses were calculated by dividing by a common ratio of about 4.5 , and set as 450 and $100 \mathrm{ppm}$, respectively.

\section{Administration period}

The rats received BZP in the diet. Administration to F0 parental animals was started from the age of five weeks old for both males and females; administration to F0 males was continued until necropsy through 10 weeks or more of the pre-mating and mating periods, while administration to F0 females lasted until necropsy through 10 weeks or more of the pre-mating, mating, gestational, and lactational periods, and during weaning of the F1 offspring (Postnatal Day: PND 21). Administration to $\mathrm{F} 1$ parental animals was started from the time of weaning (three weeks old); in F1 males it was continued until necropsy through 10 weeks or more of the pre-mating and mating periods, and in F1 females until necropsy through 10 weeks or more of the pre-mating, mating, gestational, lactational periods, and during weaning of the F2 offspring (PND 21). Administration to the non-delivering F0/F1 animals continued until necropsy, which was conducted at least 26 days after confirmation of copulation.

\section{Mating procedures}

At the age of 15 weeks after the 10 week administration period starting from five weeks old in the F0 animals, and at the age of 14-15 weeks after the 10 week or more administration period from three weeks of age in the F1 animals, females were moved to the cages of male partners in the evening, and the males and females cohabited at a sex ratio of 1:1 through the mating period. Existence of a vaginal plug or sperm in the vaginal smear was examined every morning from the following day. When either was detected, it was judged that copulation had occurred and the day was defined as gestation day (GD) 0 . The mating period was limited to two weeks. Pregnancy was confirmed by existence/absence of delivery and/or by investigating implantation sites at the time of necropsy.

For the F1 parental animals, one male and female each were selected randomly from each litter on PND 21. Necropsy of the other offspring was performed at this time. 
Reproductive toxicity study with benzophenone.

\section{Experimental design}

\section{Parental data}

1) Observation and measurment of parental animals

All adult rats were observed daily for clinical signs of toxicity, and body weight and food consumption were recorded weekly. The body weight and food consumption of copulation-confirmed females were measured on GDs $0,7,14$ and 20, on lactation days (LD) $0,4,7,14$, and at necropsy after weaning (LD 21).

\section{2) Estrous cycle}

Vaginal smears were collected from the female animals everyday in the morning to examine the estrous cycle during the two weeks before mating, starting from 13 weeks of age for the F0 parents and from 11 weeks old for the F1 parents, and the mean days of the estrous cycle were calculated. Cases with estrous cycles other than 4 to 6 days were regarded as abnormal.

\section{3) Sperm examination}

Sperm motility of ten animals of the parental animals in each F0 or F1 group was measured with a sperm auto-analyzer (HTM-IVOS Ver.10.8). In ten animals of the control and 2000 ppm groups, the number of homogenization-resistant spermatids in the testis (spermatid head counts) and number of sperm in the cauda epididymal were also counted with the sperm auto-analyzer (HTM-IVOS Ver.10.8), and smear specimens were prepared and examined for morphologically abnormal sperm to calculate the appearance rate.

\section{4) Serum hormone levels}

Six males in each treatment group of the F0 and F1 parental animals were randomly selected for hormone measurement at necropsy. Females were examined for the estrous cycle everyday in the morning after completion of the lactational period, and six females in each treatment group in the proestrous stage were randomly selected, left for about one hour after being taken out from the breeding room, and they were sacrificed to collect blood samples by decapitation without anesthesia as soon as possible after 1:00 p.m. Using sera separated from the blood samples, testosterone, FSH and LH in the males and estradiol, FSH and LH in the females were measured by the RIA method. The hormone measurement was carried out at Panapharm Laboratories Co., Ltd.

\section{5) Organ weights}

The following organs were weighed in all the F0 and F1 parental animals: the brain, pituitary gland, thyroid including parathyroid, liver, kidneys, adrenal glands, spleen, testes, epididymes (whole and caudal parts), prostate (ventral lobe), seminal vesicles (including the coagulating glands), ovaries, and uterus (including the cervical region).

\section{6) Pathological and histopathological examinations}

All the parental animals sacrificed or found dead were necropsied.

Histopathological examinations were conducted for the following organs from all males and females of the control and 2000 ppm groups in the F0 and F1 parents. The brain, pituitary gland, thyroid and parathyroid, liver, kidneys, adrenal glands, spleen, testes, epididymes, seminal vesicles (including coagulating glands), prostate (ventral lobe), ovaries, uterus (including the cervical region), vagina, and mammary glands. Furthermore, the liver and kidneys in the 100 and 450 ppm groups in the F0 and F1 parent animals and any macroscopically abnormal sites were also histopathologically examined. Besides, any animals that died during the course of the study or sacrificed upon becoming moribund were examined to investigate the causes.

\section{Litter data (offspring parameter) 1) Observation and measurment of offspring}

The pups were observed for clinical signs from the outside of the cages everyday throughout the lactation period. When the body weights were measured, they were individually and closely observed in the investigator's hands. The number of pups per litter was adjusted randomly to eight (four each of the males and females when possible) on PND 4 . When the number in a litter was less than eight, they were housed as is. The pups not selected at the adjustment were sacrificed by exposure to carbon dioxide gas and the whole bodies were stored in $10 \%$ neutral phosphate-buffered formalin solution.

Body weights were measured on PNDs 0, 4, 7, 14, and 21. The anogenital distance (AGD: the distance between the anus and the genital node) was measured on PND 4 following adjustment of the number of pups. Relative values divided by the cubic roots of the body weights on the measurement day were also calculated.

\section{2) Physical development and sexual maturation}

The incidence of pinna unfolding was calculated 
on observation of all pups from PNDs 2 to 4 . Offspring were also examined for the day on which the completion of the following occurred: upper incisor eruption from PND 6 and eye opening from PND 10 for all pups before weaning.

As indices of sexual maturation, days of preputial separation in the males and vaginal opening in the females were used, the F1 animals being individually observed during the period from PND 35 or PND 27 until completion was noted. Body weights were measured on the day of completion.

\section{3) Reflex response tests}

All live pups were examined on PND 19 for pain responses, negative geotaxis, air righting, pinna reflexes, and the positive rates were calculated.

\section{4) Organ weights (at weaning)}

The brain, thymus, and spleen of one F1 and F2 male and female pups each selected from each litter were weighed on PND 21.

\section{5) Pathological examination}

Excluding the pups that died before selection on PND 4 or the pups not selected on PND 4 (when their numbers were adjusted), all the remaining pups were necropsied when they were sacrificed or were found dead.

\section{Statistical analyses}

Data concerning effects on the offspring until their weaning were based on values calculated per litter as the specimen unit. Using weights of bilateral organs, the sums of the left and right organs were employed for statistical analysis.

Metric data were analyzed for homogeneity of variance by Bartlett's method (Bartlett, 1937). When the variance was homogeneous, one-way ANOVA was carried out. When not homogeneous, on the other hand, a Kruskal-Wallis's test (Kruskal and Wallis, 1952) was performed. When a significant inter-group difference was found, Dunnett's method (Dunnett, 1955) or a Dunnett type multiple-comparison method (Dunnett, 1964) were applied. For some examination items, the Kruskal-Wallis test was applied first, and when a significant inter-group difference was found, Dunnett type multiple-comparison method was conducted. Numerical data were analyzed by the Fisher's exact probability method (Fisher, 1955). The level of statistical significance was basically set at $5 \%$.

For clinical signs, necropsy, and histopathologi- cal findings, no statistical analyses were performed.

\section{RESULTS}

\section{Data for parental animals}

1. Chemical intake, clinical signs, body weights, and food consumption

Chemical intake data are summarized in Table 1. The mean daily intakes of the test substance in the group receiving the concentrations (doses) of 0,100 , 450 , and $2000 \mathrm{ppm}$ were equivalent to $0,6.445,29.01$, and $130.0 \mathrm{mg} / \mathrm{kg}$ for the F0 male parents, $0,8.379$, 38.15 , and $166.5 \mathrm{mg} / \mathrm{kg}$ for the $\mathrm{F} 0$ female parents, 0 , $7.785,34.60$, and $159.4 \mathrm{mg} / \mathrm{kg}$ for the $\mathrm{F} 1$ male parents, and $0,8.776,40.52$, and $179.2 \mathrm{mg} / \mathrm{kg}$ for the $\mathrm{F} 1$ female parents, respectively.

In one F1 female of the 2000 ppm group, renal papillary necrosis was observed. In this animal, emaciation was apparent two days before death and hypothermia was observed the day before death. Because histopathological examination revealed pyelectasis associated with the renal papillary necrosis, was considered to be the cause of death, it was inferred that increased pressure in the renal pelvis caused the necrosis. Since this change was not observed in the other animals, it was judged to be not related to the administration of BZP. Furthermore, no changes related to the test substance were found in any dose groups of the F0 or F1 parent in either sex.

Body weight data are shown in Fig. 1 and 2. Treatment with BZP at $450 \mathrm{ppm}$ or $2000 \mathrm{ppm}$ inhibited body weight gain and food consumption in both F0 and F1 males and females.

\section{Estrous cycle}

Data for the estrous cycle in F0 and F1 females are summarized in Table 2. Effects of BZP were not found in any dose group of the F0 and F1 females.

\section{Reproductive effects}

Reproductive data for F0 and F1 animals are summarized in Table 3. There were no effects of BZP treatment found on the number of days required for copulation, number of estrous stages missed until completion of copulation, mating index (number of the males and females showing the evidence of copulation / number of the males and females used for mating $x$ 100 ), fertility index (number of the pregnant females / number of copulated females $\times 100$ ), gestation index (number of the females with normal delivery / number of the pregnant females $\times 100$ ), or birth index (number 
Reproductive toxicity study with benzophenone.

of live pups delivered / number of implantations $\times 100$ ) in any of the F0 and F1 parental animals dose groups. Nor were effects observed for the results obtained at the time of delivery and during the lactational period.
The gestation length in each dose group was 21-23 days. When the data were compared with the background data in our laboratory (F0 parental animals: 21.7-22.3 days, F1 parental animals: 21.0-22.3 days),

Table 1. Daily Chemical intake.

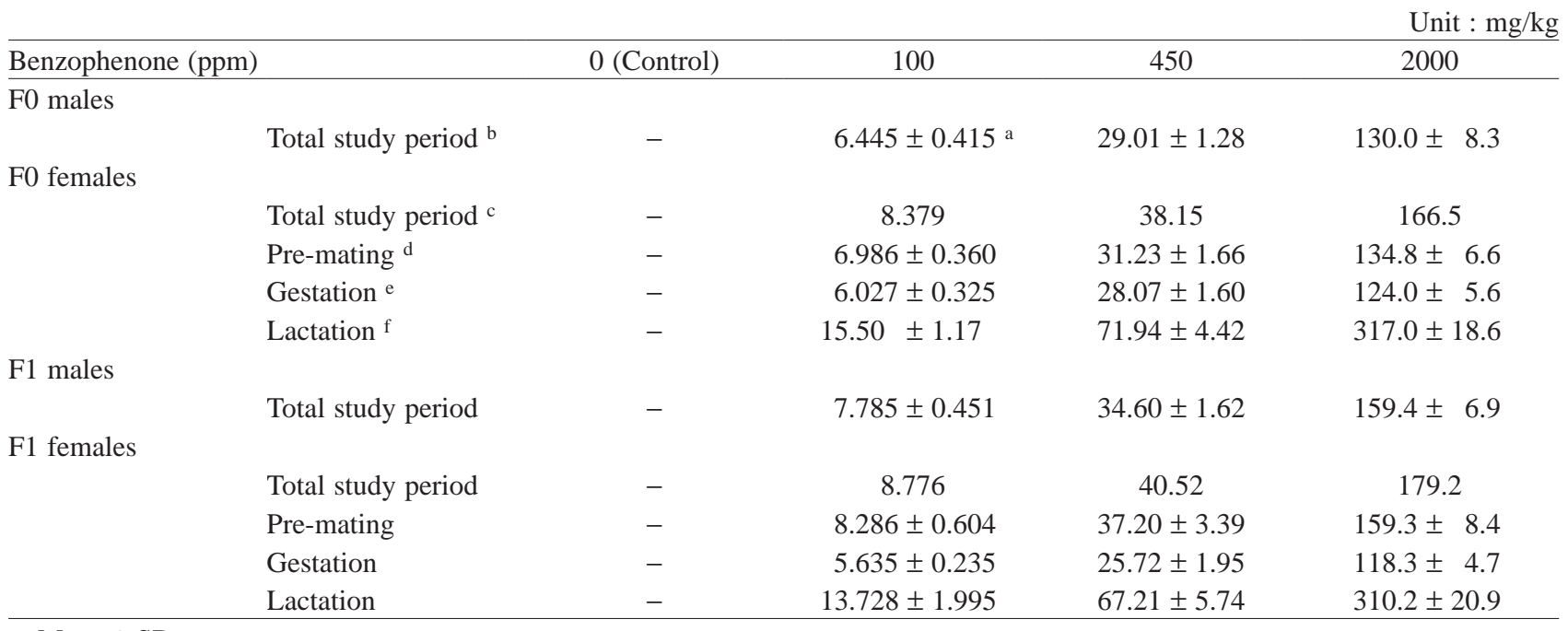

a: Mean \pm SD.

b: During the period from 10 weeks.

c: The mean daily intake for the study (pre-mating + gestation + lactation periods).

d: Pre-mating (10 weeks).

e: Gestation length (Days 21-23).

f: Lactation period (Days 0-21).
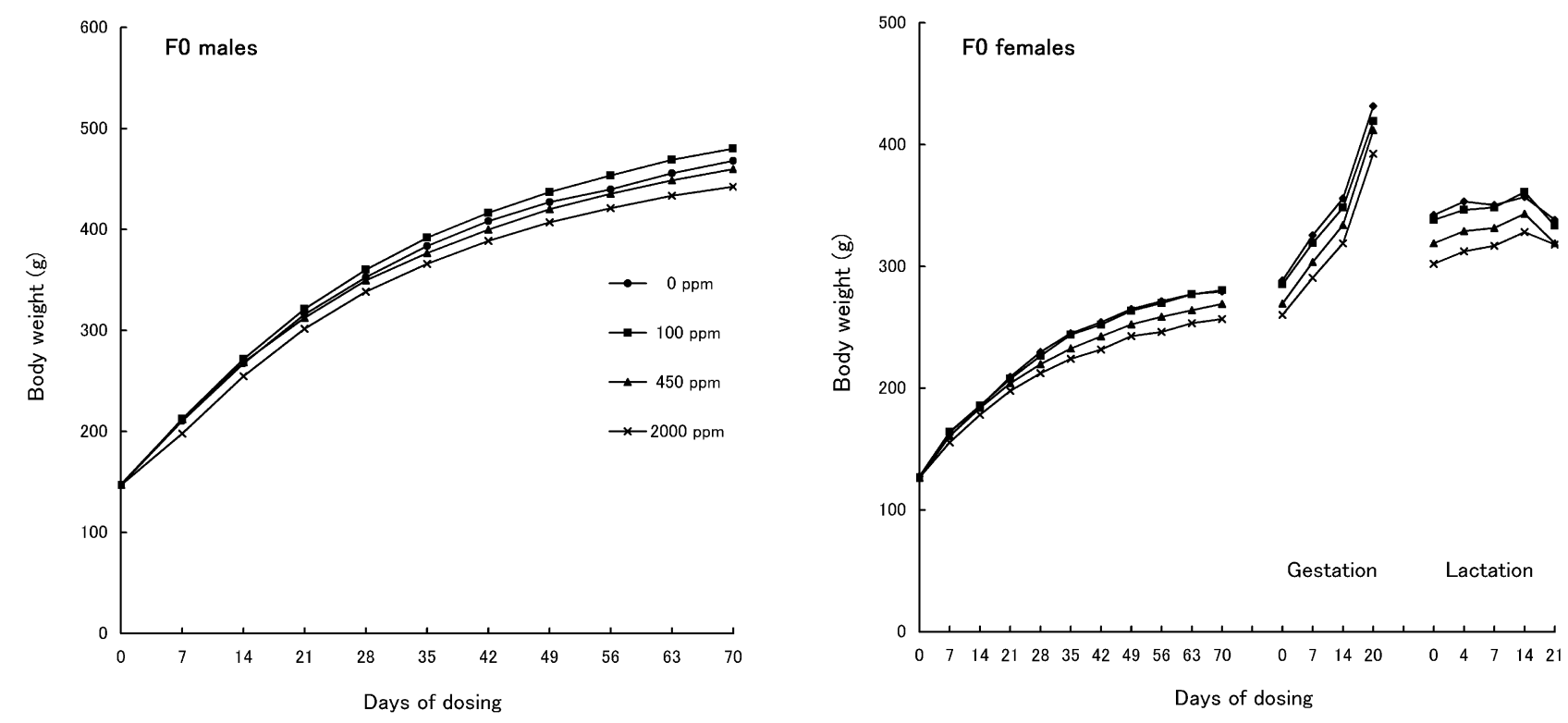

Fig. 1. Parental body weights for F0 male and females. 
the value for the F1 parents of the 2000 ppm group slightly exceeded the upper limit. However, there was no statistically significant difference from the control. Moreover, of the animals that delivered on GD 23, all females except for two (one F0 parent of the $100 \mathrm{ppm}$ group and one F1 parent of the 2000 ppm group) started to deliver at 4:00 pm on GD 22. Therefore, it is judged that the gestation length was not prolonged due to administration of BZP.

\section{Sperm parameters}

Data for sperm parameters in $\mathrm{F} 0$ and $\mathrm{F} 1$ parental males are summarized in Table 4 . In both F0 and F1 male parents, no effects of BZP treatment were found, even in the $2000 \mathrm{ppm}$ groups, on the sperm motility

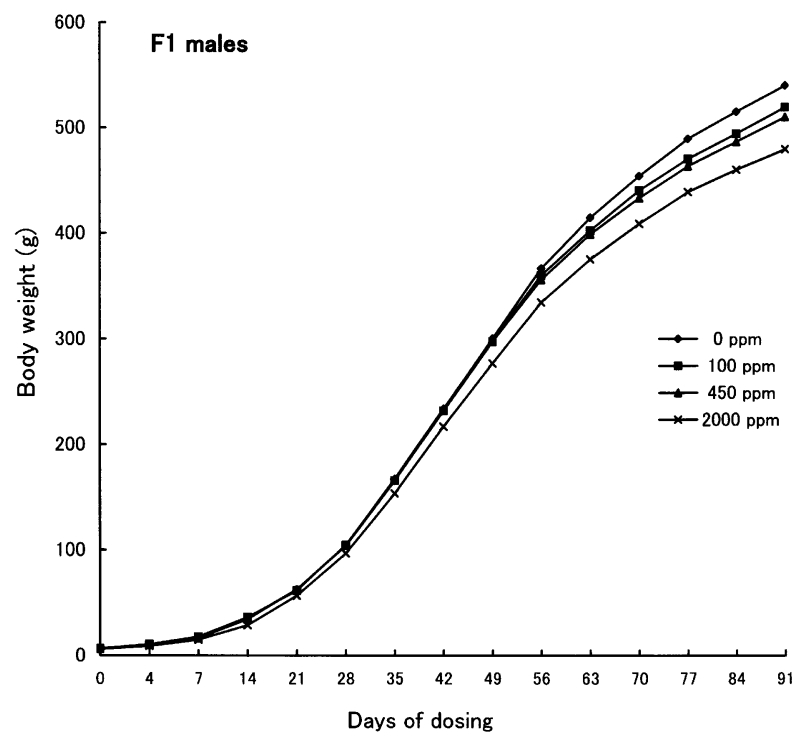

rate, number of homogenization-resistant spermatids in the testis and number of sperm in the cauda epididymis, or on the frequency of morphologically abnormal sperm.

\section{Serum hormone levels}

Results for serum hormone levels in F0 and F1 parental animals are summarized in Table 4 . In the groups receiving $100 \mathrm{ppm}$ or higher, testosterone levels in the F0 males showed a tendency to be elevated, while values for F1 males were not significantly different from the control, so that no consistent trend was apparent. In the F0 and F1 males, no effects were found with regard to the mating index or the fertility index (Table 3). Furthermore, when testosterone levels were

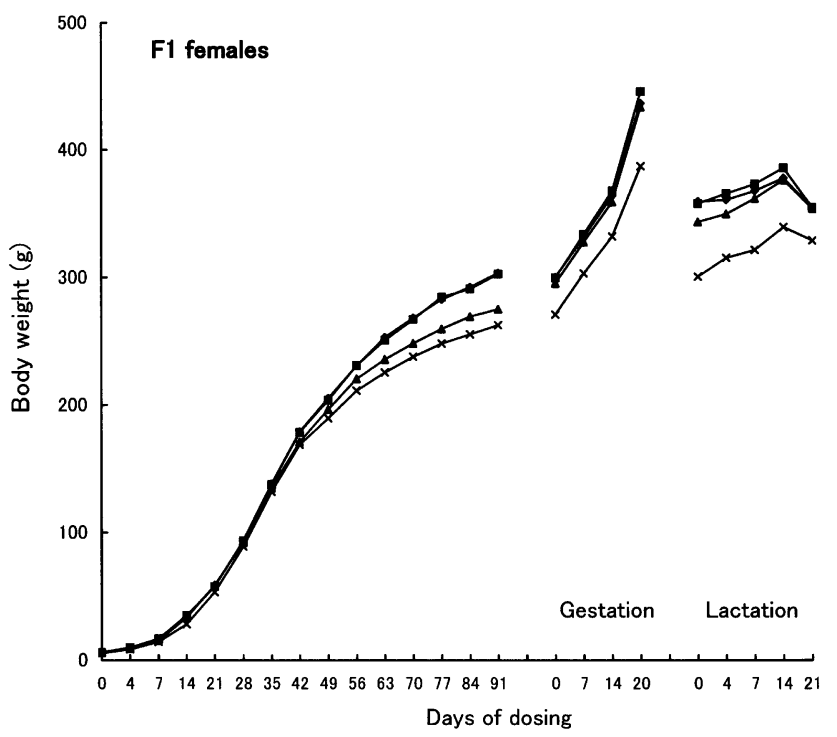

Fig. 2. Parental body weights for F1 male and females.

Table 2. Estrous cycle.

\begin{tabular}{|c|c|c|c|c|}
\hline Benzophenone (ppm) & 0 (Control) & 100 & 450 & 2000 \\
\hline \multicolumn{5}{|l|}{ F0 females } \\
\hline No. of females examined & 24 & 24 & 24 & 24 \\
\hline Mean estrous cycle (days) & $4.08 \pm 0.23$ a & $4.14 \pm 0.34$ & $4.09 \pm 0.25$ & $4.04 \pm 0.21$ \\
\hline No. of females with an abnormal estrous cycle ${ }^{b}$ & $0 / 24$ & $1 / 24$ & $1 / 24$ & $1 / 24$ \\
\hline \multicolumn{5}{|l|}{ F1 females } \\
\hline No. of females examined & 23 & 22 & 23 & 24 \\
\hline Length of estrous cycles (days) & $4.00 \pm 0.00$ & $4.15 \pm 0.33$ & $4.12 \pm 0.30$ & $4.00 \pm 0.00$ \\
\hline No. of females with an abnormal estrous cycle & $1 / 23$ & $2 / 22$ & $0 / 23$ & $2 / 24$ \\
\hline
\end{tabular}

a: Mean \pm SD.

b: Number of the females with an abnormal estrous cycle / number of females examined. 
Reproductive toxicity study with benzophenone.

Table 3. Reproductive data.

\begin{tabular}{|c|c|c|c|c|}
\hline Benzophenone (ppm) & 0 (Control) & 100 & 450 & 2000 \\
\hline \multicolumn{5}{|l|}{ F0 parents / F1 offspring } \\
\hline No. of pairs & 24 & 24 & 24 & 24 \\
\hline No. of days until copulation (days) ${ }^{b}$ & $2.0 \pm 1.2^{\mathrm{a}}$ & $2.2 \pm 1.3$ & $2.3 \pm 1.1$ & $2.0 \pm 0.9$ \\
\hline Mating index $(\%)^{\mathrm{c}}$ & 95.8 & 100.0 & 95.8 & 100.0 \\
\hline Fertility index $(\%)^{\mathrm{d}}$ & 100.0 & 95.8 & 100.0 & 100.0 \\
\hline Gestation length (days) $^{e}$ & $22.0 \pm 0.5$ & $22.1 \pm 0.4$ & $22.3 \pm 0.4$ & $22.2 \pm 0.4$ \\
\hline Gestation index $(\%)^{\mathrm{f}}$ & 100.0 & 95.7 & 100.0 & 100.0 \\
\hline Birth index $(\%) \mathrm{g}$ & 93.88 & 96.17 & 92.85 & 93.38 \\
\hline No. of implantation sites & $15.0 \pm 1.6$ & $15.2 \pm 1.3$ & $15.3 \pm 1.3$ & $13.9 \pm 2.3$ \\
\hline Total No. of offspring at birth & $14.0 \pm 1.9$ & $14.6 \pm 1.4$ & $14.5 \pm 1.9$ & $13.2 \pm 2.3$ \\
\hline No. of offspring born alive & $14.0 \pm 1.9$ & $14.6 \pm 1.4$ & $14.2 \pm 1.9$ & $12.9 \pm 2.4$ \\
\hline Sex ratio ${ }^{h}$ & 0.52 & 0.55 & 0.51 & 0.46 \\
\hline \multicolumn{5}{|l|}{ Viability index $(\%)$} \\
\hline Day $0^{\mathrm{i}}$ & $100.00 \pm 0.00$ & $100.00 \pm 0.00$ & $98.03 \pm 5.00$ & $98.01 \pm 6.65$ \\
\hline Day $4 \mathrm{j}$ & $99.14 \pm 2.29$ & $98.68 \pm 2.91$ & $99.45 \pm 1.82$ & $98.73 \pm 3.01$ \\
\hline Day 21 k & $99.46 \pm 2.61$ & $99.43 \pm 2.67$ & $100.00 \pm 0.00$ & $100.00 \pm 0.00$ \\
\hline \multicolumn{5}{|l|}{ Body weights of male offspring } \\
\hline Day 0 & $6.9 \pm 0.5$ & $6.9 \pm 0.5$ & $7.1 \pm 0.6$ & $7.4 \pm 0.5^{* *}$ \\
\hline Day 4 & $11.2 \pm 1.2$ & $11.2 \pm 0.9$ & $11.3 \pm 1.5$ & $11.1 \pm 1.3$ \\
\hline Day 7 & $18.4 \pm 1.6$ & $18.5 \pm 1.4$ & $18.6 \pm 2.0$ & $17.5 \pm 1.6$ \\
\hline Day 14 & $37.0 \pm 2.3$ & $36.8 \pm 2.5$ & $36.4 \pm 2.2$ & $33.6 \pm 2.5 * *$ \\
\hline Day 21 & $61.7 \pm 3.4$ & $60.7 \pm 4.3$ & $61.6 \pm 4.4$ & $56.0 \pm 3.7 * *$ \\
\hline \multicolumn{5}{|l|}{ Body weights of female offspring } \\
\hline Day 0 & $6.5 \pm 0.5$ & $6.6 \pm 0.5$ & $6.8 \pm 0.6$ & $6.8 \pm 0.5$ \\
\hline Day 4 & $10.6 \pm 0.9$ & $10.5 \pm 0.9$ & $10.8 \pm 1.2$ & $10.6 \pm 0.9$ \\
\hline Day 7 & $17.6 \pm 1.4$ & $17.4 \pm 1.4$ & $17.8 \pm 1.6$ & $16.8 \pm 1.3$ \\
\hline Day 14 & $35.6 \pm 2.1$ & $35.0 \pm 2.3$ & $35.2 \pm 2.2$ & $32.3 \pm 2.1 * *$ \\
\hline Day 21 & $58.4 \pm 3.4$ & $57.1 \pm 3.9$ & $58.8 \pm 4.5$ & $53.6 \pm 3.0^{* *}$ \\
\hline \multicolumn{5}{|l|}{ F1 parents / F2 offspring } \\
\hline No. of pairs & 22 & 22 & 23 & 24 \\
\hline No. of days until copulation (days) & $2.4 \pm 0.9$ & $2.6 \pm 1.2$ & $2.5 \pm 1.7$ & $2.6 \pm 1.3$ \\
\hline Mating index $(\%)$ & 86.4 & 100.0 & 100.0 & 95.8 \\
\hline Fertility index $(\%)$ & 84.2 & 95.5 & 100.0 & 100.0 \\
\hline Gestation length (days) & $22.0 \pm 0.4$ & $22.2 \pm 0.4$ & $22.2 \pm 0.4$ & $22.4 \pm 0.5$ \\
\hline Gestation index $(\%)$ & 100.0 & 100.0 & 100.0 & 100.0 \\
\hline Birth index $(\%)$ & 95.42 & 88.98 & 91.39 & 90.79 \\
\hline No. of implantation sites & $14.6 \pm 1.8$ & $16.0 \pm 2.1$ & $15.3 \pm 2.1$ & $14.5 \pm 1.6$ \\
\hline Total No. of offspring at birth & $14.1 \pm 1.8$ & $14.6 \pm 3.5$ & $14.3 \pm 1.8$ & $13.8 \pm 1.6$ \\
\hline No. of offspring born alive & $13.9 \pm 1.8$ & $14.2 \pm 3.5$ & $13.9 \pm 1.8$ & $13.1 \pm 1.5$ \\
\hline Sex ratio & 0.48 & 0.53 & 0.50 & 0.54 \\
\hline Viability index $(\%)$ & & & & \\
\hline Day 0 & $98.74 \pm 3.74$ & $97.12 \pm 4.54$ & $96.99 \pm 3.55$ & $95.22 \pm 7.99$ \\
\hline Day 4 & $99.58 \pm 1.68$ & $98.45 \pm 2.86$ & $98.91 \pm 3.02$ & $97.74 \pm 4.97$ \\
\hline Day 21 & $100.00 \pm 0.00$ & $99.40 \pm 2.73$ & $100.00 \pm 0.00$ & $100.00 \pm 0.00$ \\
\hline Body weights of male offspring & & & & \\
\hline Day 0 & $6.8 \pm 0.5$ & $7.2 \pm 0.6$ & $7.3 \pm 0.6^{*}$ & $7.4 \pm 0.4 * *$ \\
\hline Day 4 & $11.2 \pm 1.9$ & $11.4 \pm 1.5$ & $11.4 \pm 1.3$ & $11.4 \pm 1.2$ \\
\hline Day 7 & $18.7 \pm 2.2$ & $18.6 \pm 2.1$ & $18.9 \pm 1.9$ & $18.3 \pm 1.6$ \\
\hline
\end{tabular}


Table 3. Continued

\begin{tabular}{|c|c|c|c|c|}
\hline Benzophenone (ppm) & 0 (Control) & 100 & 450 & 2000 \\
\hline Day 14 & $38.4 \pm 3.7$ & $38.9 \pm 3.7$ & $37.7 \pm 3.0$ & $35.9 \pm 2.9$ \\
\hline Day 21 & $63.5 \pm 6.3$ & $65.6 \pm 6.3$ & $64.3 \pm 5.8$ & $59.1 \pm 4.6$ \\
\hline \multicolumn{5}{|l|}{ Body weights of female offspring } \\
\hline Day 0 & $6.6 \pm 0.5$ & $6.8 \pm 0.5$ & $6.9 \pm 0.6$ & $7.0 \pm 0.4^{*}$ \\
\hline Day 4 & $10.8 \pm 1.8$ & $11.0 \pm 1.3$ & $10.9 \pm 1.2$ & $10.7 \pm 1.1$ \\
\hline Day 7 & $18.0 \pm 2.1$ & $18.1 \pm 1.8$ & $18.2 \pm 1.7$ & $17.0 \pm 1.4$ \\
\hline Day 14 & $37.3 \pm 3.2$ & $37.7 \pm 2.9$ & $36.4 \pm 2.6$ & $34.0 \pm 2.6^{* *}$ \\
\hline Day 21 & $60.9 \pm 4.8$ & $63.2 \pm 5.0$ & $61.1 \pm 5.0$ & $55.7 \pm 3.6^{* *}$ \\
\hline
\end{tabular}

a: Mean \pm SD.

b: No. of days until copulation (days) = Number of days from the start of mating until the day when copulation was confirmed.

c: Mating index $(\%)=($ Number of males and females showing evidence of copulation / number of males and females used for mating) $\times 100$.

d: Fertility index $(\%)=($ Number of pregnant females / number of copulated females $) \times 100$.

e: Gestation length (days) $=$ Number of days from GD 0 till the delivery day.

f: Gestation index $(\%)=($ Number of females with normal delivery / number of pregnant females $) \times 100$.

g: Birth index $(\%)=($ Number of live pups delivered / number of implantations $) \times 100$.

h: Sex ratio $=$ Total number of male pups delivered / total number of the pups delivered.

i: Viability on PND 0 (survival rate at delivery) $(\%)=($ Number of the live pups on PND $0 /$ total number of pups delivered $) \times 100$.

j: Viability on PND 4 (the survival rate on day 4$)(\%)=($ Number of live pups on PND $4 /$ number of live pups on PND 0$) \times 100$.

k: Viability rate on PND 21 (weaning rate) $(\%)=($ Number of live pups on PND $21 /$ number of live pups on PND 4) $\times 100$.

*: Significantly different from the control value, *, $\mathrm{p}<0.05 ; * *, \mathrm{p}<0.01$.

compared between the F0 and F1 males, the treatment with BZP was found to have had no biologically significant effect. The change observed in F0 males was judged to be due to the low value in one control male. With serum levels of FSH, LH and estradiol, no change related to BZP treatment was found in any dose groups of F0 and F1 animals of either sex. In addition, no abnormalities were found in the hormone levels measured in three F1 control and one 100 ppm F1, all of which were non-copulating or non-pregnant.

\section{Organ Weight}

Organ weights for F0 and F1 parental animals are summarized in Table 7. In the 2000 ppm group, significantly elevated values were found for both the absolute and relative weights of the liver and kidneys in F0 and F1 males and females. In the 450 ppm group, a significant increase was also evident for both the absolute and relative hepatic weights and the relative renal weights in both F0 males and females; this was also the case for the absolute renal weights in F0 males, and the relative liver and kidney weights in both the F1 males and females. In the $100 \mathrm{ppm}$ group, the relative hepatic weights increased significantly in the F0 females, but there was no difference in the absolute weights. Nor was there a significant difference in absolute hepatic weights found in the F1 females.

\section{Pathological and histopathological findings}

On necropsy of the parental animals in any dose groups, no changes related to BZP treatment were found in either F0 or F1 males or females.

Histopathological findings for F0 and F1 parental animals are summarized in Table 9. Histopathological examination revealed hypertrophy of centrilobular hepatocytes in the parental F0/F1 males and females treated with $100 \mathrm{ppm}$ or higher. No differences between generations were found in the grade or incidence. In the cases with slight grade, increased eosinophilic cytoplasm was the sole observation in hypertrophied hepatocytes, while the cytoplasm appeared to be frosted glass in the cases with moderate grade. In the parental groups receiving 450 ppm or 2000 ppm, dilation of renal proximal tubules was observed in both F0 and F1 males and females. Regeneration of the proximal tubular epithelium was also apparent in all groups of F0 and F1 males and females, including the control group. The incidence of the renal change was higher in the males receiving $450 \mathrm{ppm}$ or $2000 \mathrm{ppm}$ and in the females given 2000 ppm as compared with the control, and cases with moderate or marked change were included only in the former groups. Regeneration of tubular epithelium was more remarkable in males than females, and was pathologically prevalent around the dilated tubules. 
Reproductive toxicity study with benzophenone.

Various additional histopathological changes were found in the organs/tissues of F0 and F1 males and females in the control and 2000 ppm groups, and also found at macroscopically abnormal sites in the other dose groups. However, these changes all known to occur spontaneously in toxicity studies in rats, and they were all judged to be sporadic findings unrelated to the BZP treatment. Abnormalities attributable in cases of non-copulate/non-pregnancy were not recognized at either necropsy on histopathological examination.

Table 4. Data from sperm parameters and hormone levels.

\begin{tabular}{|c|c|c|c|c|c|c|c|c|c|c|c|c|}
\hline \multirow{2}{*}{$\begin{array}{l}\text { Benzophenone }(\mathrm{ppm}) \\
\text { F0 parents }\end{array}$} & \multicolumn{3}{|c|}{0 (Control) } & \multicolumn{3}{|c|}{100} & \multicolumn{3}{|c|}{450} & \multicolumn{3}{|c|}{2000} \\
\hline & & & & & & & & & & & & \\
\hline \multicolumn{13}{|l|}{ Sperm examination } \\
\hline No. of males examined & \multicolumn{3}{|c|}{10} & \multicolumn{3}{|c|}{10} & \multicolumn{3}{|c|}{10} & \multicolumn{3}{|c|}{10} \\
\hline Sperm motility (\%) & 92.4 & \pm & $4.74 \mathrm{a}$ & 93.1 & \pm & 5.30 & 95.1 & \pm & 3.45 & $92.1=$ & \pm & 3.96 \\
\hline $\begin{array}{r}\text { Homogenization-resistant spermatids }\left(\times 10^{6} / \mathrm{g}\right) \\
\text { (spermatid head counts in the testis) }\end{array}$ & 112.9 & \pm 2 & 20.69 & & - & & & - & & $105.5=$ & \pm 1 & 16.24 \\
\hline Sperm Count $\left(\times 10^{6} / \mathrm{g}\right),($ cauda epididymal $)$ & 487.5 & $\pm 1^{\prime}$ & 75.89 & & - & & & - & & $530.3=$ & \pm 17 & 71.79 \\
\hline Abnormal sperm (\%) & 0.6 & \pm & 0.46 & & - & & & - & & $0.3=$ & \pm & 0.42 \\
\hline Tailless sperm (\%) & 2.1 & \pm & 3.03 & & - & & & - & & $1.7=$ & \pm & 2.00 \\
\hline \multicolumn{13}{|l|}{ Hormone levels } \\
\hline No. of males examined & & 6 & & & 6 & & & 6 & & & 6 & \\
\hline Testosterone (ng/mL) & 1.47 & & 0.52 & 2.94 & \pm & 1.76 & 2.95 & \pm & 1.79 & $3.65=$ & \pm & 1.17 \\
\hline FSH (ng/mL) & 8.84 & & 1.45 & 9.99 & \pm & 1.99 & 8.94 & \pm & 1.28 & $9.89=$ & & 0.91 \\
\hline LH (ng/mL) & 1.69 & & 0.13 & 1.73 & \pm & 0.28 & 1.54 & \pm & 0.29 & $1.59=$ & \pm & 0.24 \\
\hline No. of females examined & & 6 & & & 6 & & & 6 & & & 6 & \\
\hline FSH (ng/mL) & 6.51 & & 1.19 & 6.38 & \pm & 0.92 & 6.08 & \pm & 1.52 & $6.94=$ & \pm & 0.56 \\
\hline LH (ng/mL) & 1.86 & & 0.13 & 1.79 & \pm & 0.39 & 1.80 & \pm & 0.15 & $1.83=$ & \pm & 0.30 \\
\hline Estradiol (pg/mL) & 69.0 & \pm 2 & 23.0 & 72.8 & & 3.7 & 82.8 & \pm 2 & 8.0 & $96.5=$ & \pm 3 & 34.6 \\
\hline \multicolumn{13}{|l|}{ F1 parents } \\
\hline \multicolumn{13}{|l|}{ Sperm examination } \\
\hline No. of males examined & \multicolumn{3}{|c|}{10} & \multicolumn{3}{|c|}{10} & \multicolumn{3}{|c|}{10} & \multicolumn{3}{|c|}{10} \\
\hline Sperm motility (\%) & 94.5 & \pm & 4.90 & 93.6 & \pm & 4.14 & 94.9 & \pm & 3.63 & $92.2=$ & \pm & 3.58 \\
\hline $\begin{array}{l}\text { Homogenization-resistant spermatids }\left(\times 10^{6} / \mathrm{g}\right) \\
\text { (spermatid head counts in the testis) }\end{array}$ & 139.3 & \pm & 46.18 & & - & & & - & & $108.4=$ & \pm 2 & 26.42 \\
\hline Sperm Count $\left(\times 10^{6} / \mathrm{g}\right),($ cauda epididymal $)$ & 584.0 & $\pm 1^{\prime}$ & 75.53 & & - & & & - & & $664.8=$ & \pm 10 & 09.93 \\
\hline Abnormal sperm $(\%)$ & 0.9 & \pm & 1.02 & & - & & & - & & $1.0=$ & \pm & 0.83 \\
\hline Tailless sperm (\%) & 1.9 & \pm & 1.85 & & - & & & - & & $0.6=$ & \pm & 0.70 \\
\hline \multicolumn{13}{|l|}{ Hormone levels } \\
\hline No. of males examined & & 6 & & & 6 & & & 6 & & & 6 & \\
\hline Testosterone (ng/mL) & 3.51 & \pm & 1.26 & 3.59 & \pm & 1.52 & 2.98 & \pm & 1.18 & $2.70=$ & & 1.36 \\
\hline FSH (ng/mL) & 9.16 & \pm & 2.42 & 9.20 & \pm & 1.11 & & \pm & 0.53 & $9.19=$ & \pm & 1.46 \\
\hline LH (ng/mL) & 1.78 & \pm & 0.49 & 1.80 & \pm & 0.50 & 1.49 & \pm & 0.25 & $1.60=$ & \pm & 0.44 \\
\hline No. of females examined & & 6 & & & 6 & & & 6 & & & 6 & \\
\hline FSH (ng/mL) & 5.88 & \pm & 1.03 & 6.44 & \pm & 0.39 & 6.32 & \pm & 0.66 & $5.86=$ & \pm & 0.82 \\
\hline LH (ng/mL) & 1.53 & & 0.38 & 1.87 & \pm & 0.22 & 1.98 & \pm & 0.49 & $1.72=$ & \pm & 0.17 \\
\hline Estradiol (pg/mL) & 85.0 & \pm 2 & 26.9 & 85.7 & & 25.5 & 93.5 & & 6.7 & $95.2=$ & \pm 4 & 49.7 \\
\hline
\end{tabular}

a: Mean \pm SD.

-: Not examined.

*: Significantly different from the control value, *, $\mathrm{p}<0.05 ; * *, \mathrm{p}<0.01$. 


\section{Effects on the growth and development of offspring 1. Clinical signs and body weights}

In the $\mathrm{F} 1$ and $\mathrm{F} 2$ offspring, no changes related to BZP treatment were found in clinical signs in any dose group.

Body weight data are summarized in Table 3 (body weight gain values are included). In the 2000 ppm groups, significant elevation was noted for body weights on PND 0 in F1 male and F2 male/female offspring, while significantly low values were found as follows: for body weights on PNDs 14-21 in the F1 and F2 male/female offspring and for body weight gain on PNDs 7-21 in F1 male/female and F2 female offspring. In the $450 \mathrm{ppm}$ group, the F2 male offspring showed significantly elevated body weights on PND 0 . In the $100 \mathrm{ppm}$ group, normal body weight changes as shown in the control were observed in both $\mathrm{F} 1$ and $\mathrm{F} 2$ male and female offspring.

\section{Viability index, AGD, reflex/response tests, and external examination}

Viability indexes for offspring are summarized in Table 3, and the AGD values for F1 and F2 pups and results of reflex/response tests, as well as external examination, are summarized in Table 5. No changes related to BZP treatment were found in the number of $\mathrm{F} 1$ and F2 pups delivered, the viabilities on PNDs 0,4 and 21, and the other parameter examined. In the 2000 ppm group, although a significant difference was noted in the sex ratio of F1 pups (the males were fewer than the females) before adjustment of the number of F1 pups, there was no difference in the sex ratio on PND 0 , and an equivalent trend was not recognized in the F2 pups. Therefore, this change was considered to be sporadic and unrelated to $\mathrm{BZP}$.

\section{Physical development}

Finding for physical development of F1 and F2 offspring are summarized in Table 6. In the 2000 ppm group, a significantly higher incidence of pinna unfolding was found on PND 2 in male and female F1 and F2 pups and on PND 3 in female F2 pups. In the 450 ppm group, a significantly higher incidence of pinna unfolding was also found on PND 2 in F1 males and females and F2 males, and on PND 3 in F2 female pups. With BZP treatment at $450 \mathrm{ppm}$ or higher, the age on the day when the pinna unfolding appeared tended to be younger in F1 and F2 pups. Considering that the number of F0 and F1 dams delivering on GD 23 tended increase as compared with the control, this change was judged apparent unrelated to BZP treatment (Table 3).
In addition, there were no changes related to BZP treatment regarding the day of occurrence of incisor eruption (upper incisor eruption) or eye opening in F1 and F2 pups, and for the timing as well as body weights on the days of vaginal opening in F1 females or preputial separation in F1 males.

\section{Organ weights}

Organ weight data for F1 and F2 offspring are summarized in Table 8 . In the 2000 ppm group, significantly elevated relative brain weights were observed in both male and female F1/F2 pups, and lower absolute spleen weights were found in both F1 sexes. These changes were considered due to inhibition of the body weight gain induced by the administration of BZP. In the groups treated with $450 \mathrm{ppm}$ or less, no substance related changes were found.

\section{Necropsy findings}

No changes related to BZP treatment were observed in any dose group of F1 and F2 pups.

\section{DISCUSSION}

Regarding effects of BZP on the F0 and F1 parental animals in the present study, changes such as inhibition of body weight gain and food consumption, increase in renal weights and dilatation and regeneration of renal proximal tubules were recognized in the groups receiving $450 \mathrm{ppm}$ or $2000 \mathrm{ppm}$, and increase in the hepatic weights and centrilobular hepatocytic hypertrophy were observed in the $100 \mathrm{ppm}$ or higher groups. These changes were generally in line with the report of Burdock et al. (1991). When BZP was administered to rats at the dose of $20 \mathrm{mg} / \mathrm{kg} /$ day for 90 days or at the doses of 100 or $500 \mathrm{mg} / \mathrm{kg} /$ day for 28 days, inhibition of the body weight gain, increased relative liver and kidney weights and centrilobular hepatocyte hypertrophy were thus evident (Burdock et al., 1991). Regarding the dilatation of renal proximal tubules, this is known to occur with injury insufficient to cause necrosis (Greaves., 1990a). Although severe injury such as necrosis of the tubular epithelium was not found in the present study, BZP clearly influenced the proximal tubular epithelium. The centrilobular hepatocytic hypertrophy is considered to be an adaptive vital reaction as a consequence of the induction of drugmetabolizing enzymes (Gopinath et al., 1987; Greaves., 1990b). Although there have been previous reports of potential effects of BZP on the endocrine system, only weak estrogenic, as well as weak anti- 
Reproductive toxicity study with benzophenone.

Table 5. Data for anogenital distance, reflex/response and external examination of offspring.

\begin{tabular}{|c|c|c|c|c|}
\hline Benzophenone (ppm) & 0 (Control) & 100 & 450 & 2000 \\
\hline \multicolumn{5}{|l|}{ F1 pups } \\
\hline No. of males examined & 23 & 22 & 23 & 24 \\
\hline $\operatorname{AGD}^{b}(\mathrm{~mm})^{\mathrm{c}}$ & $4.267 \pm 0.400^{\mathrm{a}}$ & $4.182 \pm 0.413$ & $4.193 \pm 0.433$ & $4.150 \pm 0.376$ \\
\hline $\mathrm{AGD} / \mathrm{BW}^{1 / 3 \mathrm{~d}}$ & $1.911 \pm 0.157$ & $1.870 \pm 0.172$ & $1.873 \pm 0.178$ & $1.865 \pm 0.157$ \\
\hline No. of females examined & 23 & 22 & 23 & 24 \\
\hline $\mathrm{AGD}(\mathrm{mm})$ & $2.177 \pm 0.179$ & $2.014 \pm 0.188^{*}$ & $1.959 \pm 0.208^{* *}$ & $2.055 \pm 0.286$ \\
\hline AGD/BW ${ }^{1 / 3}$ & $0.993 \pm 0.086$ & $0.919 \pm 0.080 *$ & $0.886 \pm 0.082 * *$ & $0.936 \pm 0.125$ \\
\hline \multicolumn{5}{|l|}{ Reflex / response (males) } \\
\hline Pain response $(\%)$ & 100 & 100 & 100 & 100 \\
\hline Midair righting reflex $(\%)$ & 100 & 100 & 100 & 100 \\
\hline Negative geotaxis $(\%)$ & 100 & 100 & 100 & 100 \\
\hline Pinna reflex $(\%)$ & 100 & 100 & 100 & 100 \\
\hline \multicolumn{5}{|l|}{ Reflex / response (females) } \\
\hline Pain response $(\%)$ & 100 & 100 & 100 & 100 \\
\hline Midair righting reflex $(\%)$ & 100 & 100 & 100 & 100 \\
\hline Negative geotaxis $(\%)$ & 100 & 98.9 & 100 & 100 \\
\hline Pinna reflex $(\%)$ & 100 & 100 & 100 & 100 \\
\hline \multicolumn{5}{|l|}{ External examination (males) } \\
\hline No anomaly & $169 / 23^{e}$ & $175 / 22$ & $171 / 23$ & $145 / 24$ \\
\hline \multicolumn{5}{|l|}{ External examination (females) } \\
\hline No anomaly & $154 / 23$ & $146 / 22$ & $162 / 23$ & $171 / 23$ \\
\hline Omphalocele & $0 / 0$ & $0 / 0$ & $0 / 0$ & $1 / 1$ \\
\hline \multicolumn{5}{|l|}{ F2 pups } \\
\hline No. of males examined & 16 & 21 & 23 & 23 \\
\hline AGD (mm) & $4.149 \pm 0.416$ & $4.089 \pm 0.415$ & $4.077 \pm 0.265$ & $3.968 \pm 0.227$ \\
\hline AGD/BW $1 / 3$ & $1.855 \pm 0.119$ & $1.821 \pm 0.142$ & $1.817 \pm 0.106$ & $1.767 \pm 0.067$ \\
\hline No. of females examined & 16 & 21 & 23 & 23 \\
\hline $\mathrm{AGD}(\mathrm{mm})$ & $1.918 \pm 0.152$ & $1.955 \pm 0.199$ & $1.967 \pm 0.169$ & $1.882 \pm 0.133$ \\
\hline AGD/BW $1 / 3$ & $0.870 \pm 0.052$ & $0.879 \pm 0.077$ & $0.890 \pm 0.082$ & $0.857 \pm 0.057$ \\
\hline \multicolumn{5}{|l|}{ Reflex / response (males) } \\
\hline Pain response $(\%)$ & 100 & 100 & 100 & 100 \\
\hline Midair righting reflex $(\%)$ & 100 & 100 & 100 & 100 \\
\hline Negative geotaxis $(\%)$ & 100 & 100 & 100 & 100 \\
\hline Pinna reflex $(\%)$ & 100 & 100 & 100 & 100 \\
\hline \multicolumn{5}{|l|}{ Reflex / response (females) } \\
\hline Pain response $(\%)$ & 100 & 100 & 100 & 100 \\
\hline Midair righting reflex $(\%)$ & 100 & 100 & 100 & 100 \\
\hline Negative geotaxis $(\%)$ & 100 & 100 & 100 & 100 \\
\hline Pinna reflex $(\%)$ & 100 & 100 & 100 & 100 \\
\hline \multicolumn{5}{|l|}{ External examination (males) } \\
\hline No anomaly & $109 / 16$ & $161 / 21$ & $166 / 23$ & $172 / 23$ \\
\hline \multicolumn{5}{|l|}{ External examination (females) } \\
\hline No anomaly & $115 / 15$ & $145 / 21$ & $164 / 23$ & $145 / 23$ \\
\hline Rudimentary tail & $1 / 1$ & $0 / 0$ & $0 / 0$ & $0 / 0$ \\
\hline
\end{tabular}

a: Mean \pm SD.

b: AGD was measured on PND (postnatal day) 4.

c: Distance between the anus and genital node ( $\mathrm{mm}$ ).

d: The relative AGD value divided by the cubic root of the body weight on the measurement day was also calculated.

e: Number of offspring / number of parent animals (dams).

*: Significantly different from the control value, *, $\mathrm{p}<0.05 ; * *, \mathrm{p}<0.01$. 
Table 6. Data for physical development of the offspring and sexual maturation.

\begin{tabular}{|c|c|c|c|c|}
\hline Benzophenone (ppm) & 0 (Control) & 100 & 450 & 2000 \\
\hline \multicolumn{5}{|l|}{ F1 pups } \\
\hline \multicolumn{5}{|l|}{ Physical development } \\
\hline \multicolumn{5}{|l|}{ Pinna unfolding $(\%)$} \\
\hline No. of males examined & 23 & 22 & 23 & 24 \\
\hline Day 2 & $31.8 \pm 41.2^{\mathrm{a}}$ & $54.8 \pm 39.6$ & $65.3 \pm 42.1^{*}$ & $75.3 \pm 29.6^{* *}$ \\
\hline Day 3 & $95.0 \pm 18.9$ & $94.3 \pm 15.4$ & $100.0 \pm 0.0$ & $100.0 \pm 0.0$ \\
\hline Day 4 & $100.0 \pm 0.0$ & $100.0 \pm 0.0$ & $100.0 \pm 0.0$ & $100.0 \pm 0.0$ \\
\hline No. of females examined & 23 & 22 & 23 & 24 \\
\hline Day 2 & $32.1 \pm 38.1$ & $57.6 \pm 40.3$ & $73.9 \pm 35.5^{* *}$ & $75.2 \pm 32.3 * *$ \\
\hline Day 3 & $94.4 \pm 21.4$ & $96.1 \pm 18.3$ & $100.0 \pm 0.0$ & $100.0 \pm 0.0$ \\
\hline Day 4 & $100.0 \pm 0.0$ & $100.0 \pm 0.0$ & $100.0 \pm 0.0$ & $100.0 \pm 0.0$ \\
\hline \multicolumn{5}{|l|}{ Incisor Eruption } \\
\hline No. of males examined & 23 & 22 & 23 & 24 \\
\hline Age (day) ${ }^{b}$ & $10.9 \pm 1.1$ & $10.7 \pm 0.8$ & $10.7 \pm 0.6$ & $10.4 \pm 0.9$ \\
\hline No. of females examined & 23 & 22 & 23 & 24 \\
\hline Age (day) ${ }^{b}$ & $10.8 \pm 1.0$ & $10.7 \pm 0.9$ & $10.6 \pm 0.5$ & $10.3 \pm 0.8$ \\
\hline \multicolumn{5}{|l|}{ Eye opening } \\
\hline No. of males examined & 23 & 22 & 23 & 24 \\
\hline Age (day) ${ }^{b}$ & $13.9 \pm 0.5$ & $13.7 \pm 0.5$ & $13.5 \pm 0.7$ & $13.9 \pm 0.8$ \\
\hline No. of females examined & 23 & 22 & 23 & 24 \\
\hline Age (day) ${ }^{b}$ & $13.7 \pm 0.5$ & $13.5 \pm 0.7$ & $13.3 \pm 0.7$ & $13.7 \pm 0.8$ \\
\hline \multicolumn{5}{|l|}{ Sexual maturation } \\
\hline Preputial separation (Male) & 23 & 22 & 23 & 24 \\
\hline Age (day) ${ }^{b}$ & $41.6 \pm 1.4$ & $41.1 \pm 1.4$ & $41.4 \pm 1.3$ & $42.4 \pm 1.0$ \\
\hline Body Weight $(\mathrm{g})^{\mathrm{c}}$ & $229.5 \pm 16.7$ & $224.0 \pm 16.6$ & $228.7 \pm 17.7$ & $219.0 \pm 13.2$ \\
\hline Vaginal opening (Female) & 23 & 22 & 23 & 24 \\
\hline Age (day) ${ }^{b}$ & $33.2 \pm 1.3$ & $32.8 \pm 1.6$ & $33.1 \pm 1.8$ & $33.2 \pm 1.6$ \\
\hline Body Weight $(\mathrm{g})^{\mathrm{c}}$ & $126.9 \pm 11.1$ & $124.6 \pm 13.1$ & $123.1 \pm 13.5$ & $120.8 \pm 12.5$ \\
\hline \multicolumn{5}{|l|}{ F2 pups } \\
\hline \multicolumn{5}{|l|}{ Physical development } \\
\hline \multicolumn{5}{|l|}{ Pinna unfolding $(\%)$} \\
\hline No. of males examined & 16 & 21 & 23 & 23 \\
\hline Day 2 & $27.4 \pm 37.1$ & $39.0 \pm 39.5$ & $55.3 \pm 37.2 *$ & $59.3 \pm 41.8^{*}$ \\
\hline Day 3 & $93.8 \pm 15.3$ & $98.1 \pm 6.1$ & $99.5 \pm 2.6$ & $98.8 \pm 4.0$ \\
\hline Day 4 & $100.0 \pm 0.0$ & $100.0 \pm 0.0$ & $100.0 \pm 0.0$ & $100.0 \pm 0.0$ \\
\hline No. of females examined & 16 & 21 & 23 & 23 \\
\hline Day 2 & $28.7 \pm 37.1$ & $51.4 \pm 37.3$ & $55.8 \pm 35.4$ & $61.6 \pm 41.5^{*}$ \\
\hline Day 3 & $94.0 \pm 15.3$ & $97.6 \pm 10.9$ & $100.0 \pm 0.0^{*}$ & $100.0 \pm 0.0^{*}$ \\
\hline Day 4 & $100.0 \pm 0.0$ & $99.2 \pm 3.6$ & $100.0 \pm 0.0$ & $100.0 \pm 0.0$ \\
\hline \multicolumn{5}{|l|}{ Incisor Eruption } \\
\hline No. of males examined & 16 & 21 & 23 & 23 \\
\hline Age (day) & $10.7 \pm 0.7$ & $10.5 \pm 0.8$ & $11.0 \pm 0.9$ & $10.4 \pm 1.0$ \\
\hline No. of females examined & 16 & 21 & 23 & 23 \\
\hline Age (day) & $10.7 \pm 0.8$ & $10.4 \pm 0.8$ & $10.9 \pm 0.9$ & $10.5 \pm 0.9$ \\
\hline \multicolumn{5}{|l|}{ Eye opening } \\
\hline No. of males examined & 16 & 21 & 23 & 23 \\
\hline Age (day) & $13.8 \pm 0.6$ & $13.3 \pm 0.8$ & $13.5 \pm 0.5$ & $13.6 \pm 0.7$ \\
\hline No. of females examined & 16 & 21 & 23 & 23 \\
\hline Age (day) & $13.5 \pm 0.7$ & $13.3 \pm 0.8$ & $13.3 \pm 0.5$ & $13.5 \pm 0.7$ \\
\hline
\end{tabular}


Reproductive toxicity study with benzophenone.

Table 7. Organ weights for F0/F1 adults.

\begin{tabular}{|c|c|c|c|c|}
\hline \multirow{2}{*}{\multicolumn{5}{|c|}{$\begin{array}{l}\text { Benzophenone (ppm) } \\
\text { F0 adults }\end{array}$}} \\
\hline & & & & \\
\hline \multirow{4}{*}{$\begin{array}{l}\text { No. of male F0 adults examined } \\
\text { Final body weight }(\mathrm{g}) \\
\text { Brain }(\mathrm{g})\end{array}$} & 24 & 23 & 24 & 24 \\
\hline & $\pm 41.5^{\mathrm{a}}$ & $535.3 \pm 55.5$ & $515.3 \pm 35.9$ & $493.5 \pm 46.6$ \\
\hline & $2.115 \pm 0.066^{b}$ & $2.168 \pm 0.092$ & $2.150 \pm 0.082$ & $2.171 \pm 0.089$ \\
\hline & $0.408 \pm 0.030^{\mathrm{c}}$ & $0.408 \pm 0.039$ & $0.419 \pm 0.035$ & $0.443 \pm 0.039 * *$ \\
\hline \multirow[t]{2}{*}{ Pituitary gland (mg) } & $14.22 \pm 1.57$ & $14.13 \pm 1.55$ & $13.97 \pm 1.52$ & $13.20 \pm 1.73$ \\
\hline & $2.75 \pm 0.27$ & $2.65 \pm 0.30$ & $2.73 \pm 0.28$ & $2.68 \pm 0.28$ \\
\hline \multirow[t]{2}{*}{ Liver (g) } & $15.430 \pm 1.829$ & $16.629 \pm 2.363$ & $17.160 \pm 1.899 *$ & $20.383 \pm 2.672 * *$ \\
\hline & $2.968 \pm 0.252$ & $3.102 \pm 0.263$ & $3.326 \pm 0.218 * *$ & $4.127 \pm 0.314 * *$ \\
\hline \multirow{2}{*}{ Spleen $(\mathrm{g})$} & $0.790 \pm 0.110$ & $0.847 \pm 0.130$ & $0.789 \pm 0.080$ & $0.808 \pm 0.100$ \\
\hline & $0.152 \pm 0.018$ & $0.157 \pm 0.017$ & $0.153 \pm 0.014$ & $0.164 \pm 0.017 *$ \\
\hline \multirow[t]{2}{*}{ Kidneys (g) } & $3.363 \pm 0.293$ & $3.536 \pm 0.375$ & $3.727 \pm 0.371 *$ & $4.350 \pm 0.649 * *$ \\
\hline & $0.649 \pm 0.050$ & $0.663 \pm 0.058$ & $0.723 \pm 0.056^{* *}$ & $0.880 \pm 0.086^{* *}$ \\
\hline \multirow[t]{2}{*}{ Testes $(\mathrm{g})$} & $3.258 \pm 0.199$ & $3.278 \pm 0.212$ & $3.370 \pm 0.234$ & $3.388 \pm 0.268$ \\
\hline & $0.630 \pm 0.055$ & $0.616 \pm 0.057$ & $0.655 \pm 0.053$ & $0.692 \pm 0.077 * *$ \\
\hline No. of female F0 adults examined & 23 & 22 & 23 & 24 \\
\hline Final body weight (g) & $327.2 \pm 26.0$ & $324.5 \pm 24.8$ & $\pm 26.0^{*}$ & $295.7 \pm 23.3 * *$ \\
\hline \multirow[t]{2}{*}{ Brain $(\mathrm{g})$} & $1.987 \pm 0.080$ & $1.989 \pm 0.090$ & $1.971 \pm 0.079$ & $2.013 \pm 0.085$ \\
\hline & $0.610 \pm 0.044$ & $0.616 \pm 0.047$ & $0.642 \pm 0.056$ & $0.683 \pm 0.043 * *$ \\
\hline \multirow[t]{2}{*}{ Liver $(\mathrm{g})$} & $10.430 \pm 1.262$ & $10.897 \pm 1.070$ & $11.417 \pm 1.081 *$ & $14.005 \pm 1.283^{* *}$ \\
\hline & $3.183 \pm 0.209$ & $3.360 \pm 0.213^{*}$ & $3.693 \pm 0.212 * *$ & $4.736 \pm 0.267 * *$ \\
\hline Kidneys (g) & $2.149 \pm 0.203$ & $2.175 \pm 0.188$ & $2.338 \pm 0.205$ & $2.731 \pm 0.327^{* *}$ \\
\hline & $0.657 \pm 0.047$ & $0.672 \pm 0.058$ & $0.757 \pm 0.065^{* *}$ & $0.923 \pm 0.081^{* *}$ \\
\hline Ovaries (mg) & $96.04 \pm 14.90$ & $98.00 \pm 16.88$ & $94.25 \pm 13.85$ & $97.16 \pm 16.30$ \\
\hline & $29.33 \pm 3.81$ & $30.35 \pm 5.65$ & $30.52 \pm 4.22$ & $33.04 \pm 6.04$ \\
\hline F1 adults & & & & \\
\hline No. of male F1 adults examined & 22 & 22 & 23 & 24 \\
\hline Final body weight $(\mathrm{g})$ & $633.4 \pm 66.6$ & $617.1 \pm 63.9$ & $599.1 \pm 45.0$ & $562.6 \pm 48.4^{* *}$ \\
\hline Brain $(\mathrm{g})$ & $2.247 \pm 0.085$ & $2.276 \pm 0.099$ & $2.231 \pm 0.080$ & $2.257 \pm 0.106$ \\
\hline & $0.359 \pm 0.036$ & $0.373 \pm 0.033$ & $0.374 \pm 0.032$ & $0.403 \pm 0.028 * *$ \\
\hline Pituitary gland (mg) & $16.91 \pm 1.53$ & $15.89 \pm 2.05$ & $15.64 \pm 1.69^{*}$ & $15.58 \pm 1.58^{*}$ \\
\hline & $2.69 \pm 0.30$ & $2.59 \pm 0.28$ & $2.61 \pm 0.29$ & $2.78 \pm 0.28$ \\
\hline Liver $(g)$ & $18.970 \pm 3.247$ & $19.459 \pm 2.900$ & $20.220 \pm 3.079$ & $22.858 \pm 2.918 * *$ \\
\hline & $2.985 \pm 0.276$ & $3.146 \pm 0.269$ & $3.361 \pm 0.311 * *$ & $4.059 \pm 0.329 * *$ \\
\hline Spleen $(\mathrm{g})$ & $0.920 \pm 0.162$ & $0.925 \pm 0.106$ & $0.906 \pm 0.107$ & $0.907 \pm 0.138$ \\
\hline & $0.145 \pm 0.021$ & $0.151 \pm 0.014$ & $0.152 \pm 0.012$ & $0.161 \pm 0.023$ \\
\hline Kidneys (g) & $3.960 \pm 0.394$ & $3.953 \pm 0.420$ & $4.261 \pm 0.417$ & $4.984 \pm 0.562 * *$ \\
\hline & $0.682 \pm 0.057$ & $0.642 \pm 0.047$ & $0.712 \pm 0.048 * *$ & $0.889 \pm 0.093 * *$ \\
\hline Testes (g) & $3.724 \pm 0.358$ & $3.664 \pm 0.332$ & $3.751 \pm 0.224$ & $3.728 \pm 0.222$ \\
\hline & $0.596 \pm 0.096$ & $0.599 \pm 0.066$ & $0.629 \pm 0.054$ & $0.667 \pm 0.065^{* *}$ \\
\hline No. of female F1 adults examined & 16 & 21 & 23 & 22 \\
\hline Final body weight $(\mathrm{g})$ & $348.9 \pm 25.4$ & $352.2 \pm 27.6$ & $329.6 \pm 32.4$ & $306.4 \pm 23.2 * *$ \\
\hline Brain $(g)$ & $2.005 \pm 0.112$ & $2.054 \pm 0.070$ & $2.020 \pm 0.076$ & $2.064 \pm 0.089$ \\
\hline & $0.578 \pm 0.055$ & $0.586 \pm 0.043$ & $0.618 \pm 0.064$ & $0.676 \pm 0.043 * *$ \\
\hline Liver $(\mathrm{g})$ & $12.393 \pm 1.378$ & $12.877 \pm 1.553$ & $13.556 \pm 1.687$ & $16.236 \pm 1.879 * *$ \\
\hline & $3.553 \pm 0.292$ & $3.656 \pm 0.328$ & $4.111 \pm 0.277 * *$ & $5.301 \pm 0.486^{* *}$ \\
\hline Kidneys (g) & $2.359 \pm 0.143$ & $2.460 \pm 0.193$ & $2.584 \pm 0.292$ & $3.060 \pm 0.356^{* *}$ \\
\hline & $0.679 \pm 0.056$ & $0.700 \pm 0.059$ & $0.784 \pm 0.054 * *$ & $0.999 \pm 0.077 * *$ \\
\hline Ovaries (mg) & $112.73 \pm 15.46$ & $118.79 \pm 11.41$ & $112.80 \pm 16.32$ & $117.62 \pm 16.19$ \\
\hline & $32.46 \pm 4.72$ & $33.83 \pm 3.31$ & $34.35 \pm 4.59$ & $38.40 \pm 4.67 * *$ \\
\hline
\end{tabular}

a: Mean \pm SD.

b: Absolute organ weight.

c: Relative organ weight.

*: Significantly different from the control value, *, $\mathrm{p}<0.05$; **, $\mathrm{p}<0.01$. 
N. HOSHINO et al.

estrogenic action was observed in uterotrophic assays (METI, 2002). No adverse effects seemingly related to these actions were observed in this two-generation reproductive toxicity study. With regard to reproductive toxicity in F0 and F1 parental animals, there were no obvious effects even at the highest dose of 2000 ppm.

As for effects on F1 and F2 offspring, inhibition of the body weight gain was observed at the dose of 2000 ppm.

Therefore, from the present study of BZP administered to rats over two-generations, the no observed effect level (NOEL) on the parental animals is concluded to be less than $100 \mathrm{ppm}$. Concerning effects on the endocrine system and reproductive toxicity in parental animals, the NOEL is $2000 \mathrm{ppm}$. In terms of

Table 8. Organ weights for F1/F2 weanlings.

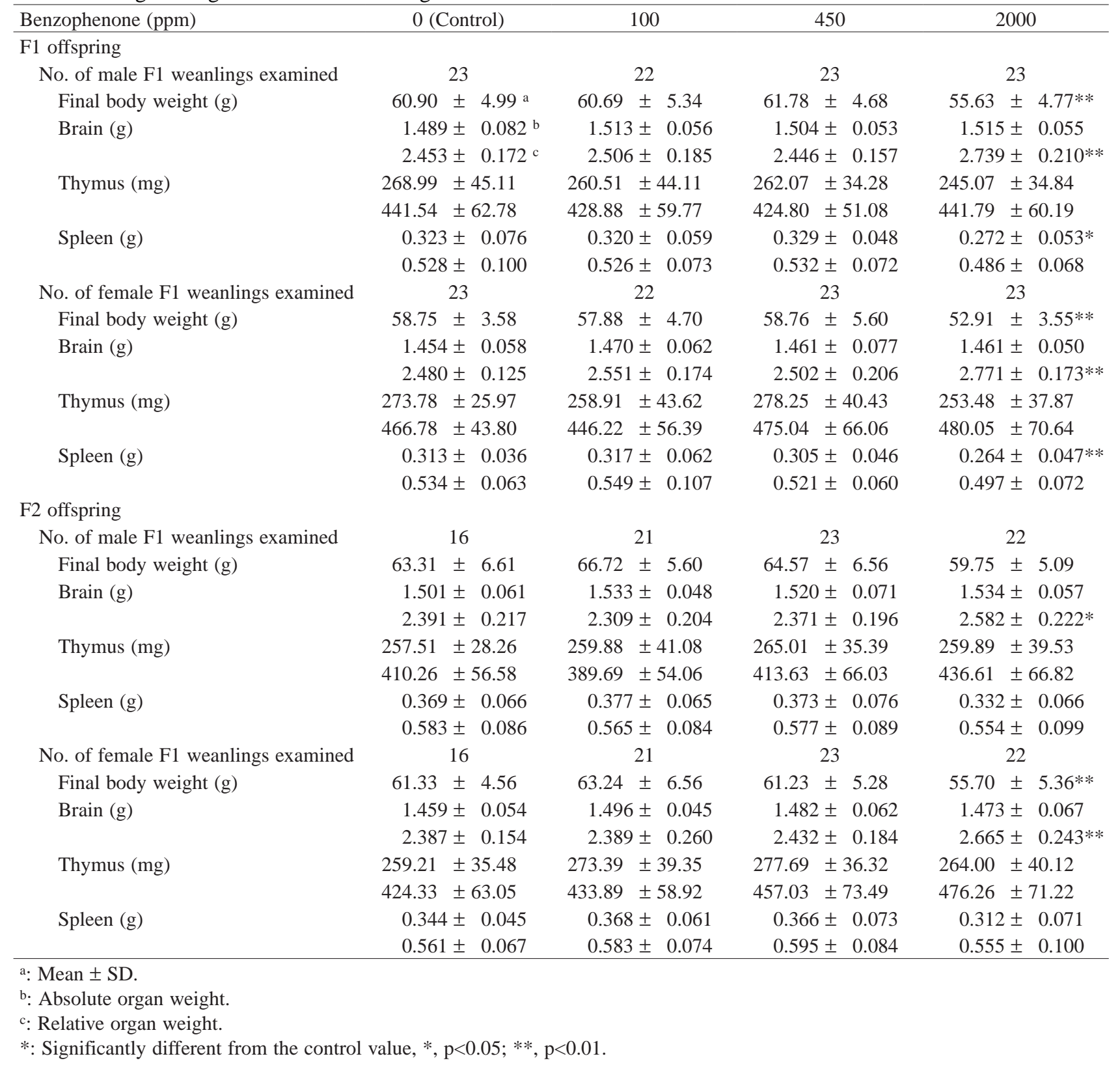


Reproductive toxicity study with benzophenone.

Table 9. Histopathological findings for F0/F1 adults.

\begin{tabular}{|c|c|c|c|c|c|c|c|c|c|}
\hline \multirow{2}{*}{ Benzophenone (ppm) } & \multicolumn{5}{|c|}{ Male } & \multicolumn{4}{|c|}{ Female } \\
\hline & & 0 (Control) & 100 & 450 & 2000 & 0 (Control) & 100 & 450 & 2000 \\
\hline \multicolumn{10}{|l|}{ F0 adults } \\
\hline No. of F0 adults examined & & 24 & 23 & 24 & 24 & 24 & 24 & 24 & 24 \\
\hline \multicolumn{10}{|l|}{ Liver } \\
\hline \multirow[t]{2}{*}{ Hypertrophy, centrilobular hepatocytes } & + & 0 & 9 & 24 & 0 & 0 & 4 & 21 & 0 \\
\hline & ++ & 0 & 0 & 0 & 24 & 0 & 0 & 0 & 24 \\
\hline \multicolumn{10}{|l|}{ Kidney } \\
\hline Dilatation, proximal tubule & + & 0 & 0 & 1 & 11 & 0 & 0 & 4 & 18 \\
\hline \multirow[t]{3}{*}{ Regeneration, proximal tubular epithelium } & + & 17 & 17 & 15 & 2 & 7 & 9 & 9 & 14 \\
\hline & ++ & 0 & 0 & 7 & 20 & 0 & 0 & 0 & 1 \\
\hline & +++ & 0 & 0 & 0 & 1 & 0 & 0 & 0 & 0 \\
\hline \multicolumn{10}{|l|}{ F1 adults } \\
\hline No. of F1 adults examined & & 22 & 22 & 23 & 24 & 23 & 22 & 23 & 23 \\
\hline \multicolumn{10}{|l|}{ Liver } \\
\hline \multirow[t]{2}{*}{ Hypertrophy, centrilobular hepatocytes } & + & 0 & 9 & 22 & 4 & 0 & 7 & 23 & 0 \\
\hline & ++ & 0 & 0 & 1 & 20 & 0 & 0 & 0 & 23 \\
\hline \multicolumn{10}{|l|}{ Kidney } \\
\hline Dilatation, proximal tubule & + & 0 & 0 & 1 & 13 & 0 & 0 & 1 & 17 \\
\hline \multirow[t]{3}{*}{ Regeneration, proximal tubular epithelium } & + & 14 & 14 & 14 & 6 & 7 & 6 & 8 & 15 \\
\hline & ++ & 0 & 0 & 6 & 16 & 0 & 0 & 0 & 1 \\
\hline & +++ & 0 & 0 & 0 & 2 & 0 & 0 & 0 & 0 \\
\hline
\end{tabular}

+, Slight; ++, Moderate; +++, Severe.

the effects on the offspring, the NOEL is considered to be $450 \mathrm{ppm}$.

\section{ACNOWLEDGMENT}

The present study was supported by the Ministry of Economy, Trade and Industry, Japan. The authors are grateful to the members of Mitsubishi Chemical Safety Institute who have been involved in this study.

\section{REFERENCES}

Bartlett, M.S. (1937): Properties of sufficiency and statisical tests. Proc. Roy. Soc., A160, 268-282.

Burdock, G.A., Pence, D.H. and Ford, R.A. (1991): Safety evaluation of benzophenone. Food. Chem. Toxicol., 29, 741-750.

Dunnett, C. W. (1955): A multiple comparison procedure for comparing several treatments with a control. J. Am Stat. Assoc., 50, 1096-1121.

Dunnett, C. W. (1964): New tables for multiple comparison with a control. Biometrics, 20, 482-492.

Fisher, R. A. (1955): Statistical methods and scientific induction. J.R. Stat. Soc. [B], 17, 69-78.

Gopinath, C., Prentice D.E. and Lewis, D.J. (1987):
Atlas of Experimental Toxicological Pathology. The liver, pp. 43-60, MTP Press Limited, Lancaster, England.

Greaves, P. (1990 a) Histopathology of Preclinical Toxicity Studies: Interpretation and Relevance in Drug Safety Evaluation. Urinary Tract. Kidney, pp. 497-554, New York.

Greaves, P. (1990 b): Histopathology of Preclinical Toxicity Studies: Interpretation and Relevance in Drug Safety Evaluation. Digestive System 2. Liver, pp. 393-441, New York.

Kruskal, W.H. and Wallis, W.A. (1952): Use of ranks in one-criterion variance analysis. J. Am. Statist. Assoc., 47, 583-621.

METI (2002): Current Status of Testing Methods Development for Endocrine Disruptors. Ministry of Economy, Trade and Industry, Japan.

Nakagawa, Y., Suzuki, T. and Tayama, S. (2000): Metabolism and toxicity of benzophenone in isolated rat hepatocytes and estrogenic activity of its metabolites in MCF-7 cells. Toxicology, 156, 27-36.

Nishihara, T., Nishikawa, J., Kanayama, T., Dakeyama, F., Saito, K., Imagawa, M.,Takatori, S., Kitagawa, Y., Hori, S. and Utsumi, H. 
N. HOSHINO et al.

(2000): Estrogenic activities of 517 chemicals by yeast two-hybrid assay. J. Health Sci., 46, 282-298.

OECD (1983): Guidelines for testing of chemicals,
Section 4-Health Effects, Guideline No.416. Organization for Economic Co-operation and Development, May 26, 1983. 